\title{
ESCOLHA PROFISSIONAL DE ALUNOS DO ENSINO MEDIO: UM ESTUDO NA ÁREA RURAL
}

\section{Leonor M Santana ${ }^{1}$ \\ Edna Maria Querido de Oliveira Chamon²}

Resumo: Este trabalho tem por objetivo identificar os elementos que permeiam as escolhas profissionais de jovens estudantes do ensino médio, em escolas públicas da área rural. Para tanto foi realizada pesquisa de campo, descritiva e exploratória, com abordagem qualitativa e quantitativa. A amostra foi composta por 114 alunos, em duas cidades da Região Metropolitana do Vale do Paraíba Paulista. Os dados foram coletados por meio de questionários, entrevistas semiestruturadas e aplicação de um jogo de aplicabilidade em processos de orientação profissional. Os dados obtidos por meio do questionário foram tabulados pelo software Sphinx®. Os conteúdos obtidos pelas entrevistas foram tabulados pelo software ALCESTE. O Jogo foi analisado de acordo com os critérios já definidos neste instrumento. Para análise utilizou-se a técnica de Triangulação, permitindo articular os dados obtidos pelas diferentes ferramentas. Os resultados permitiram revelar a influência do contexto urbano de forma significativa no discurso destes jovens, na medida em que não relacionam as atividades características do contexto rural entre as opções a escolher. Palavras-chave: Escolha Profissional; Educação do Campo; Ensino Médio.

\footnotetext{
${ }^{1}$ Mestranda do Programa em Educação e Desenvolvimento Humano da Universidade de Taubaté, Brasil. E-mail: leonor.santana@gmail.com.

2 Coordenadora do Programa de Pós-Graduação em Educação e Desenvolvimento Humano da Universidade de Taubaté, Brasil. E-mail: edna.chamon@gmail.com.
} 